RESEARCH PAPER RP1468

Part of Journal of Research of the National Bureau of Standards, Volume 28, May 1942

\title{
ELIMINATION OF OXIDE FILMS ON FERROUS MATE- RIALS BY HEATING IN VACUUM
}

\author{
By Vernon C. F. Holm
}

\begin{abstract}
An investigation of the mechanism by which lightly oxidized specimens of ferrous materials were brightened when heated in vacuum showed that the presence of carbon was essential. Oxidized specimens of iron containing small amounts of carbon were brightened in 15 to 20 minutes at $800^{\circ} \mathrm{C}$, and the elimination of the oxide film was accompanied by decreases in the carbon content. Cleanup of oxide films on stainless steel occurred also when the specimens were heated to about $1,050^{\circ} \mathrm{C}$. Oxidized high-purity iron which contained less than 0.001 percent of carbon could not be brightened by vacuum heating at temperatures up to $1,250^{\circ} \mathrm{C}$. Vacuum heating of lightly oxidized specimens of high-purity iron sometimes caused the oxide film to agglomerate, forming distinct, geometric patterns that could be observed under the microscope.
\end{abstract}

\section{CONTENTS}

Page

I. Introduction

II. Materials and method _._.

III. Possible explanations for the elimination of oxide films _._.

1. Dissociation of oxides_._._. _...

2. Volatilization of oxides

3. Absorption of oxide films_.._.

4. The role of carbon

IV. Structures of oxide films on high-purity iron_._.

V. Summary

VI. References

\section{INTRODUCTION}

In the manufacture of certain metal products where shaping is accomplished by cold-forming operations, it is often necessary to relieve the stresses by annealing. In some processes the products may be heated at specified temperatures for developing desirable physical properties, as in aging and hardening treatments. However, most metals when heated in air form oxide films or scale that are often unsightly and may interfere with subsequent manufacturing operations. In many instances the final product must have a bright surface finish. In such cases it is a decided advantage if surface oxidation can be avoided and costly pickling and polishing operations eliminated. On the other hand, the heat treatment of metals without surface oxidation is not always a simple matter, as it involves both the selection and the careful maintenance of suitable atmospheres in which 
the concentrations of oxygen are held below the required limits. The amount of oxygen that can be tolerated varies greatly with different metals and even for plain carbon steels the atmospheres are sometimes adjusted to compensate for differences in carbon content. Since oxidation may occur through the action of gaseous oxides, as well as elemental oxygen, the partial pressures of water vapor, carbon dioxide, and even carbon monoxide, require close control. The harmful action of water vapor was particularly emphasized in a recent paper by Gillett and Gonser [1]. ${ }^{1}$

In the bright annealing of stainless steels, extreme precautions are necessary and the partial pressure of oxygen must be kept at a very low value. This has been accomplished, in some cases, by the use of atmospheres formed by cracking anhydrous ammonia. Such atmospheres obviously have a high percentage of hydrogen and would tend to cause decarburization at the temperatures necessary for annealing. However, recent work [2] on the effect of hydrogen in iron and steel has demonstrated that heating a metal in the gas may have other harmful effects. The use of some chemically inert gas would be the ideal solution of the problem except that the removal of the last traces of oxygen presents difficulties. Utilization of vacuum furnaces as a means of obtaining inert environments for annealing has been suggested, but for practical reasons these appear applicable only in relatively few instances. However, because vacuum heating ${ }^{2}$ offers a means of investigating the changes that occur during bright annealing without the effect of the usual gas-metal equilibria, it was felt that such a study might provide some pertinent information regarding the behavior of metals in inert atmospheres at high temperatures.

Some preliminary experiments on vacuum bright annealing were reported in an earlier paper [3]. It was shown that bright specimens of stainless steels became tarnished when heated in vacuum at $800^{\circ} \mathrm{C}$, whereas specimens of plain steels remained bright. In the temperature range $950^{\circ}$ to $1,250^{\circ} \mathrm{C}$, stainless steels could be heated without tarnishing. Further, it was shown that tarnished specimens of plain carbon steels were brightened by heating at $800^{\circ} \mathrm{C}$, whereas tarnished stainless steels generally were brightened only at temperatures above $1,000^{\circ} \mathrm{C}$. In the subsequent discussion of the paper several possible explanations for the brightening were suggested, as follows:

1. The oxide dissociates into metal and oxygen.

2 . The oxide volatilizes.

3. The oxide is absorbed or dissolved in the body of the metal.

4. The oxide combines with the carbon of the metal and is eliminated as carbon monoxide.

The earlier experiments have been extended to ascertain which of these suggested mechanisms was responsible for the elimination of the oxide films.

\section{MATERIALS AND METHOD}

In the present work a study was made of changes in weight of specimens during oxidation and in subsequent vacuum heating. In some instances the changes in weight were correlated with changes in oxygen content as determined by vacuum fusion. Carbon determinations were made on some of the specimens to indicate the possible

1 Figures in brackets indicate the literature references at the end of this paper.

2 The term "vacuum heating" refers to the heating of a specimen or specimens in vacuum. 
role of this element. It was desirable to use specimens of large surface area and at the same time not to exceed certain space limitations, both in the vacuum-heating furnace and in the vacuum-fusion apparatus. This was accomplished by the use of thin strip specimens in the form of coils. It was necessary, in many instances, to subject the coiled specimens to several cycles, each consisting in oxidation in air at a suitable temperature followed by heating in vacuum. In the subsequent discussion these cycles are referred to as "oxidation and vacuumheating cycles." The materials that were used are listed in table 1.

TABLE 1.-Materials used in studying the effect of vacuum heating on oxidized specimens

\begin{tabular}{|c|c|c|c|c|c|}
\hline Specimen & Material & Thickness & Oxygen & Carbon & Remarks \\
\hline & High-purity iron ${ }^{1}$ & $m m_{0.06}$ & $\begin{array}{r}\text { Percent } \\
0.006\end{array}$ & $\begin{array}{r}\text { Percent } \\
0.001\end{array}$ & \\
\hline & High-purity iron ${ }^{1}$ & .10 & .003 & .001 & \\
\hline $3 \ldots$ & Electrolytic iron & .15 & .002 & .013 & $\begin{array}{l}\text { Cathode iron melted in Arsem } \\
\text { furnace, forged, and cold-rolled }\end{array}$ \\
\hline $4 \ldots$. & Electrolytic iron & .15 & .002 & .039 & $\begin{array}{l}\text { Cathode iron melted in Arsem } \\
\text { furnace with small carbon addi- } \\
\text { tions, forged, and cold-rolled to } \\
0.15 \mathrm{~mm} \text {. }\end{array}$ \\
\hline $\begin{array}{l}5 \\
6 \ldots \ldots\end{array}$ & $\begin{array}{l}\text { Open-hearth iron } \\
\text { Stainless steel }\end{array}$ & .09 & .10 & .02 & Total impurities about $0.3 \%$. \\
\hline & Staminss steel. ........ & .22 & .014 & & $18.5 \%$ Cr; $8.2 \%$ N1. \\
\hline
\end{tabular}

1 Prepared by Thompson and Cleaves [4]; total impurities, about 0.01 percent.

Specimens 2 to $2.5 \mathrm{~cm}$ wide and 15 to $20 \mathrm{~cm}$ long were cut from cold-rolled strip material and were cleaned by swabbing with ether, then rinsing consecutively with carbon tetrachloride, alcohol, and ether. They were dried in an oven at about $60^{\circ} \mathrm{C}$ for a few minutes and were cooled in a desiccator. Before weighing, the strips were loosely coiled on a clean $3 / 16$-in. steel rod, so that the diameter of the entire coil did not exceed $1 \mathrm{~cm}$. During oxidation the specimens were suspended in a vertical silica tube heated in a resistance furnace. Since the ends of the tube were not tightly closed, an ample supply of air was available for oxidation. Temperatures of about $400^{\circ} \mathrm{C}$ were used for the irons and about $800^{\circ} \mathrm{C}$ for the stainless steel. The progress of oxidation was determined by periodic inspections, and the specimens were removed from the furnace when a blue temper color had developed. Oxidation was usually completed in from 5 to 15 minutes under these conditions, but occasionally more time was required for the stainless steel. The oxidized specimens were cooled in a desiccator before weighing.

The vacuum heating was performed in the vacuum furnace previously described [3]. This consisted of a vacuum-tight silica tube mounted vertically within a high-frequency induction coil. Low pressures were obtained by means of a mercury diffusion pump used in conjunction with a rotary oil pump. The coiled specimen was held in a suspended iron thimble that was heated by induction and maintained at the desired temperature for 15 to 20 minutes. After cooling in the vacuum furnace, the specimen was reweighed. Sometimes when a specimen was treated through several oxidation and vacuum-heating cycles, a sample coupon was clipped from the outer coil at each stage so that the progressive changes in the appearance of the specimen could be observed with greater ease. Some of the 
coils were opened after oxidation or after vacuum heating to ascertain the uniformity of the treatment. In no case was any significant difference observed in different portions of the coil.

\section{POSSIBLE EXPLANATIONS FOR THE ELIMINATION OF OXIDE FILMS}

\section{DISSOCIATION OF OXIDES}

Although dissociation of the oxide under these conditions of low pressure and high temperature appears, at first glance, to offer the simplest explanation for the elimination of the oxide film on an oxidized specimen, this mechanism is not in line with either theoretical considerations or observed facts. In the case of a more noble metal, like copper, the dissociation pressure of the oxide at temperatures comparable to those used is great enough so that an oxide film would decompose in a vacuum. However, according to Mellor [5] the dissociation pressure of $\mathrm{FeO}$ is of the order of $10^{-9} \mathrm{~mm}$ of mercury at $1,400^{\circ} \mathrm{C}$ and only $10^{-14} \mathrm{~mm}$ at $1,000^{\circ} \mathrm{C}$. At present, no devices are known by which a vacuum of even $10^{-9} \mathrm{~mm}$ of mercury can be produced or measured. It is theoretically possible that vapors of metals whose oxides have lower dissociation pressures, for example chromium, might combine with oxygen and reduce the pressure sufficiently so that even iron oxide could dissociate. However, this would require ideal conditions, and in an apparatus that has not been especially conditioned for extremely low pressure work, it is not probable that the pressure would be reduced by this means below thelimits obtainable with a mercury diffusion pump. In the present experiments, "clean-up" of films on iron specimens took place without the presence of any chromium in the furnace, which indicates that the mechanism of clean-up did not involve any function of this element.

Some experiments on specimens of the materials listed in table 1 illustrated the changes in weight that occurred during oxidation and subsequent vacuum heating. Oxidized specimens of electrolytic and open-hearth iron were vacuum-heated at $800^{\circ} \mathrm{C}$, and the stainless steels were heated at $1,000^{\circ}$ to $1,050^{\circ} \mathrm{C}$, just as in the experiments described in the previous paper. These temperatures were found to permit satisfactory clean-up of the oxide films in 15 to 20 minutes. The high-purity irons were also vacuum-heated at 1,000 to $1,050^{\circ} \mathrm{C}$; but in no case did the high-purity materials brighten completely with this treatment, although the blue temper color gave way to a gray metallic appearance. The error in the preliminary experiments of mistaking this for true brightening was indicated when microscopic inspection showed that the oxide had not been eliminated.

As a rule, the gain in weight during oxidation was about $0.0005 \mathrm{~g}$ for each specimen of iron. The losses in vacuum heating were slightly higher, averaging about $0.0008 \mathrm{~g}$, except for the high-purity materials, which showed no appreciable decrease. Some of the specimens of stainless steel gained as much as $0.0015 \mathrm{~g}$ in oxidation and lost about twice this amount when heated in vacuum; other specimens behaved like the irons. These data are noteworthy in that they show that materials which were brightened during vacuum heating lost more weight in this treatment than had been gained in oxidation. Although the difference was not great, the results were consistent. If simple 
dissociation could account for the elimination of the oxide film, the losses in weight should have been approximately equal to the gains during oxidation. The most important observation, however, was that the oxide film on high-purity iron could not, in any instance, be removed by vacuum heating. If dissociation of oxides could account for the clean-up of oxide films on ferrous specimens, the same effect should have been obtained on high-purity iron as on less pure ferrous materials during vacuum heating. However, the behavior of the high-purity iron was strikingly different. In view of these observations and by consideration of the extremely low dissociation pressure of iron oxide, it appears that the dissociation of oxides could not have been a significant factor in the brightening of oxidized specimens during vacuum heating.

\section{VOLATILIZATION OF OXIDES}

The possibility that volatilization of an oxide film may be responsible for its removal during vacuum heating was pointed out by Gonser [6] on the basis of experiments at the Battelle Memorial Institute. In his experiments, lightly oxidized strips of stainless steel were heated by the passage of a heavy electric current to a temperature estimated at $1,250^{\circ}$ to $1,350^{\circ} \mathrm{C}$ in a vacuum produced by a mechanical pump. The hottest portions of the specimens were brightened during the heating, and the accompanying loss was stated to be three or more times the gain in weight during oxidation. As the oxide film disappeared from the specimen, a dark deposit appeared on the walls on the enclosing glass tube. In the light of these observations, Gonser made the logical assumption that the oxide film had been eliminated by volatilization.

In the present experiments on stainless steel, which were performed at somewhat lower temperatures, about $1,050^{\circ} \mathrm{C}$, although a dark film on the inner walls of the furnace was sometimes observed, the losses in weight during vacuum heating were not great enough to account for the elimination of the oxide film in the form of a metallic oxide. Furthermore, in repeated experiments involving alternate oxidation and vacuum heating of the same specimen, a stage was reached when the specimen would no longer brighten. If volatilization were the correct explanation for the removal of the oxide film on stainless steel, it should be possible to carry the process through numerous cycles and not be hindered, as was the case, by the apparent depletion of some element in the material. The black deposit on the furnace walls was probably formed from volatilized metal that subsequently may or may not have oxidized. In the present investigation, considerable deposition of condensed iron was observed on the inner walls of the furnace tube when specimens of high-purity iron were heated above $1,200^{\circ} \mathrm{C}$.

Specimens of high-purity iron could not be brightened by heating at $1,250^{\circ} \mathrm{C}$, under the same conditions which resulted in the brightening of stainless steels; and one specimen that was heated at $1,250^{\circ} \mathrm{C}$ for 20 minutes did not clean up, although it lost 2 percent of its weight through vaporization.

The inability of stainless steel specimens to clean up after a few cycles of oxidation and vacuum heating and the fact that in no case could specimens of high-purity iron be completely brightened, even 
at $1,250^{\circ} \mathrm{C}$, suggests that some other factor, and not volatilization, was responsible for the elimination of the oxide film on a ferrous specimen. It is not denied that some volatilization of oxide may have occurred, but the evidence obtained indicates that this cause alone was not adequate to account for complete brightening in any one of the specimens.

\section{ABSORPTION OF OXIDE FILMS}

Because iron can form a solid solution with oxygen, there is some reason for assuming that the observed brightening of oxidized specimens may have resulted, at least partially, from simple absorption of the surface oxides by the underlying metal. Rhines [7] stated that in bright annealing operations on certain copper alloys, internal oxidation may occur when sufficient oxygen is present in the atmosphere, even though the surface remains clear and bright. In a recent investigation by Rogers and Stamm [8] on the determination of the $A_{3}$ point in high-purity iron, it is reported that a small specimen that had been slightly oxidized while it was being sealed into an evacuated silica bulb regained its bright appearance after being held at temperatures near the $A_{3}$ point for about 4 hours. In this case the weight of oxygen involved amounted to about 0.003 percent, and the authors concluded that the clean-up was probably due to absorption of oxide in the metal.

The data in the literature on the solid solubility of oxygen in iron are rather scanty and somewhat inconsistent, and do not afford definite information concerning the solubility at various temperatures. However, experiments were carried out to show whether or not sufficient oxide could be absorbed to account for the brightening of oxidized specimens under the conditions of vacuum heating that have been considered here. The experiments already described have shown that oxidized specimens of high-purity iron could not be completely brightened by vacuum heating and that no significant loss in weight occurred. Furthermore, vacuum-fusion determinations of oxygen in specimens of high-purity iron that had been oxidized and vacuumheated at $800^{\circ}, 940^{\circ}$, and at $1,020^{\circ} \mathrm{C}$ definitely indicated that the oxygen acquired during oxidation was not lost during subsequent vacuum heating. It is evident that absorption of the oxide films in the underlying metal would not affect the weight or oxygen content of the specimen.

In order to investigate the possibility that, in spite of the incomplete brightening, some of the oxide may have dissolved in the iron, it was decided to make oxygen determinations on high-purity iron specimens that had been oxidized and vacuum-heated, and also to ascertain the amount of oxygen that remained after such specimens had been pickled for removal of the oxides on the surface. The difference in oxygen content of the pickled specimen and the original material would represent the amount of oxygen absorbed during vacuum heating.

In order to provide favorable conditions for solution of oxygen in high-purity iron, specimens were subjected to several cycles of oxidation at $400^{\circ}$ and vacuum heating at $1,050^{\circ}$ C. A specimen of high-purity iron No. 1 (table 1) was uncoiled and cut in halves after three cycles. One half was pickled for 1 minute in hydrochloric acid 
containing a commercial inhibitor, preceding the vacuum-fusion determination. The unpickled portion was found to contain 0.120 percent of oxygen, whereas the value for the pickled portion, 0.010 percent, was only slightly greater than the oxygen content of the original material, 0.006 percent. A determination on a pickled specimen of high-purity iron No. 2 (table 1) after six cycles indicated an oxygen content of 0.003 percent, which was comparable to the value obtained on an untreated specimen of this sample. These results indicate that an insignificant amount of oxygen dissolved in the high-purity iron under conditions which brightened other ferrous materials.

Some additional vacuum-fusion determinations are of interest in this connection because they illustrate the differences in behavior of ordinary iron and high-purity iron during vacuum heating. The oxygen content of a specimen of electrolytic iron No. 3 (table 1) increased from 0.004 to 0.016 percent during light oxidation, and after vacuum heating, only 0.005 percent of oxygen remained. Likewise, the oxygen content of a specimen of electrolytic iron No. 4 (table 1) increased from 0.002 to 0.007 percent in a light oxidizing treatment, but after vacuum heating, the specimen contained only 0.003 percent. In both instances, complete brightening occurred during vacuum heating, practically all of the oxygen picked up in the oxidizing treatment was eliminated during vacuum heating, and the increase in oxygen content above the original value was negligible. According to these experiments the elimination of oxide films was not dependent upon the absorption of oxide by the underlying metal, and in the case of highpurity iron, the amount absorbed was far too minute to cause any significant brightening.

\section{THE ROLE OF CARBON}

The experiments up to this point have shown that the three suggested causes - dissociation, volatilization, and absorption of oxidesplayed an insignificant part in the elimination of oxide films on ferrous specimens during vacuum heating. It remained now to investigate the fourth suggested mechanism, the role of carbon in the vacuum brightening of oxidized specimens. In the previous paper [3] it was suggested that carbon might be involved in the reaction that caused brightening, but no direct experimental evidence to that effect was shown. In his discussion of the paper, Gonser reported that stainless steel which after vacuum heating for removal of oxide film was cooled slowly to facilitate precipitation of carbides contained fewer carbide particles than the original material. This was an indication that carbon had taken part in the elimination of the oxide films.

In the present experiments, specimens of three materials of known carbon contents were subjected to numerous cycles of oxidation and vacuum heating. The electrolytic irons were vacuum-heated, as usual, at $800^{\circ} \mathrm{C}$, and the stainless steel at about $1,050^{\circ} \mathrm{C}$. Each specimen consisted of a coiled strip weighing about $6 \mathrm{~g}$. After treatment, the carbon contents were redetermined. The results are presented in table 2 . 
TABLE 2.-Changes in carbon content of electrolytic iron and a stainless steel during oxidation and vacuum heating treatments

[For the electrolytic iron each cycle consisted in oxidation at $400^{\circ} \mathrm{C}$ and vacuum heating at $800^{\circ} \mathrm{O}$. Oxidation of the stainless steel was accomplished at about $800^{\circ} \mathrm{C}$ and vacuum heating at approximately $1,050^{\circ} \mathrm{C}$.]

\begin{tabular}{|c|c|c|c|}
\hline Material & $\begin{array}{l}\text { Number of } \\
\text { cycles }\end{array}$ & $\begin{array}{l}\text { Original car- } \\
\text { bon content }\end{array}$ & $\begin{array}{c}\text { Final carbon } \\
\text { content }\end{array}$ \\
\hline $\begin{array}{l}\text { Electrolytic iron No. } 3 \\
\text { Electrolytic iron No. } 4 \\
\text { Electrolytic iron No. } 4 \\
\text { Stainless steel No. } 6\end{array}$ & $\begin{array}{l}3 \\
3 \\
6 \\
5\end{array}$ & $\begin{array}{r}\text { Percent } \\
0.013 \\
.039 \\
.039 \\
.07\end{array}$ & $\begin{array}{r}\text { Percent } \\
0.005 \\
.012 \\
.004 \\
.01\end{array}$ \\
\hline
\end{tabular}

It is evident that in each case the vacuum heating was associated with a definite decrease in carbon content. Of the four specimens, each carried an oxide coating after the last vacuum heating, except one specimen of electrolytic iron No. 4, which had been subjected to only three cycles of oxidation and vacuum heating. At this stage, the specimen still retained 0.012 percent of carbon, which apparently was sufficient to effect complete brightening. When the carbon content had reached a level of only 0.004 or 0.005 percent, however, as in electrolytic iron No. 3 after three cycles, and electrolytic iron No. 4 after six cycles, brightening no longer occurred. The stainless steel brightened satisfactorily in the first one or two cycles, but as the carbon content dropped from 0.07 to 0.01 percent in the course of the treatment, the ability to eliminate the oxide film was lost.

The results of these experiments support the conclusion that the oxide films were eliminated through reaction with the carbon in the specimens, apparently to form carbon monoxide. The necessary supply of carbon at the surface was presumably maintained by diffusion from beneath, until the carbon content became so low that the rate of the reaction was negligible. This was shown in a run on electrolytic iron No. 4 in which a sample coupon was clipped from the specimen at each stage in the treatment. Figure 1 is a photograph of these coupons, which are representative of the changes in surface appearance of this material during six successive cycles of oxidation and vacuum heating. It is evident that the material after the first three cycles was quite bright but subsequently became darker with each treatment, and, after the last one, showed definite evidence of oxide. The dark streaks which appear on some of the specimens are due to surface irregularities that developed during coiling and uncoiling, and these should not be confused with the changes in general appearance that occurred during the thermal treatments. The untreated specimen, which had not been coiled, appears smooth and bright over its entire surface. The carbon content of the original material was 0.039 percent, and in the final vacuum heating this was presumably reduced to 0.004 or 0.005 percent.

The change in appearance of a specimen of high-purity iron in a similar run is shown in figure 2 . In this case the vacuum heating was at $1,050^{\circ} \mathrm{C}$. The vacuum-heated specimen at the left, which had not been oxidized, is the only one that is completely bright, and after each oxidation the vacuum-heated specimens showed increasing evidence of the oxide film. In the third cycle there is very little difference between the appearance of the oxidized specimen and that of the 


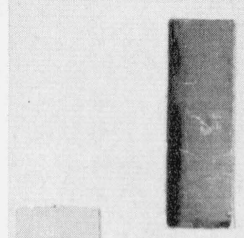

la

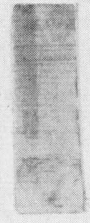

20

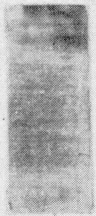

$3 a$

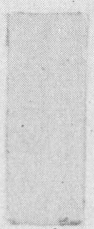

$3 b$

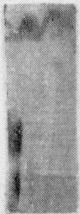

40

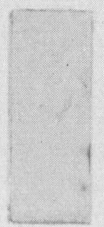

$4 b$

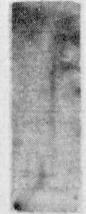

$5 a$

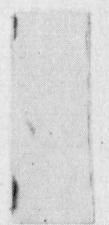

I b

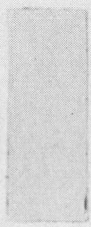

$2 b$

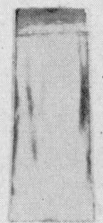

$5 b$
6 a

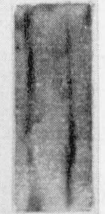

FIGURE 1.-Changes in the appearance of electrolytic iron during six successive cycles of oxidation at $400^{\circ} \mathrm{C}$. and vacuum heating at $800^{\circ} \mathrm{C}$.

$1 a$ represents the appearance of the specimen after the first oxidation, whereas $1 b$ illustrates the appearance of the oxidized specimen after vacuum heating in the first cycle. The coupon at the extreme left shows

the appearance of the untreated material.

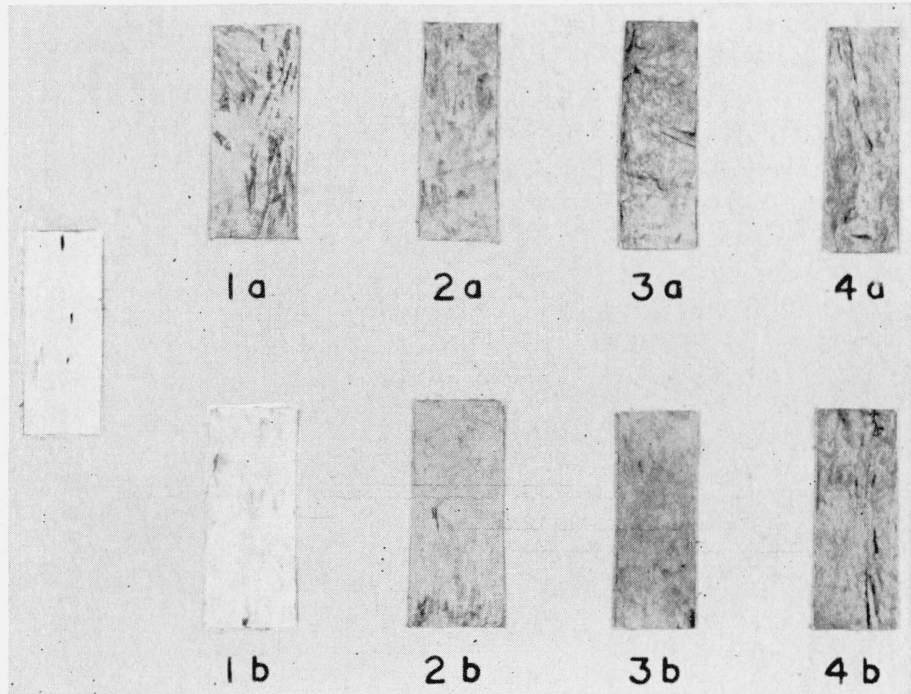

FIGURE 2.-Changes in the appearance of high-purity iron during four sucessive cycles of oxidation at $400^{\circ} \mathrm{C}$. and vacuum heating at $1,050^{\circ} \mathrm{C}$.

The specimen at the extreme left illustrates the appearance of the specimen after heating in vacuum without prior oxidation. 1 a represents the appearance of the specimen after the first oxidation, whereas $1 b$ represents the appearance of the oxidized specimen after vacuum heating in the first cycle. 
vacuum-heated specimen. A comparison of figure 1 and figure 2 serves to illustrate the effect of carbon in the elimination of oxide films. It should be kept in mind that the electrolytic iron was heated at only $800^{\circ} \mathrm{C}$, whereas the high-purity iron was heated at $1,050^{\circ} \mathrm{C}$.

The manner in which the behavior of the different ferrous materials varied with the initial carbon content is shown graphically in figure 3. Curve $A$, for high-purity iron, indicates a gradual net gain in weight for the specimen, due to the fact that the losses during vacuum heating were negligible. Curve $B$, for electrolytic iron with 0.039 percent of carbon, shows a slight decrease in weight for the first four cycles. In subsequent cycles the carbon content was apparently too low to effect any significant loss of oxygen during the heating in vacuum, and the specimen gained in weight in the same manner as the highpurity iron. The final carbon content was 0.004 percent.

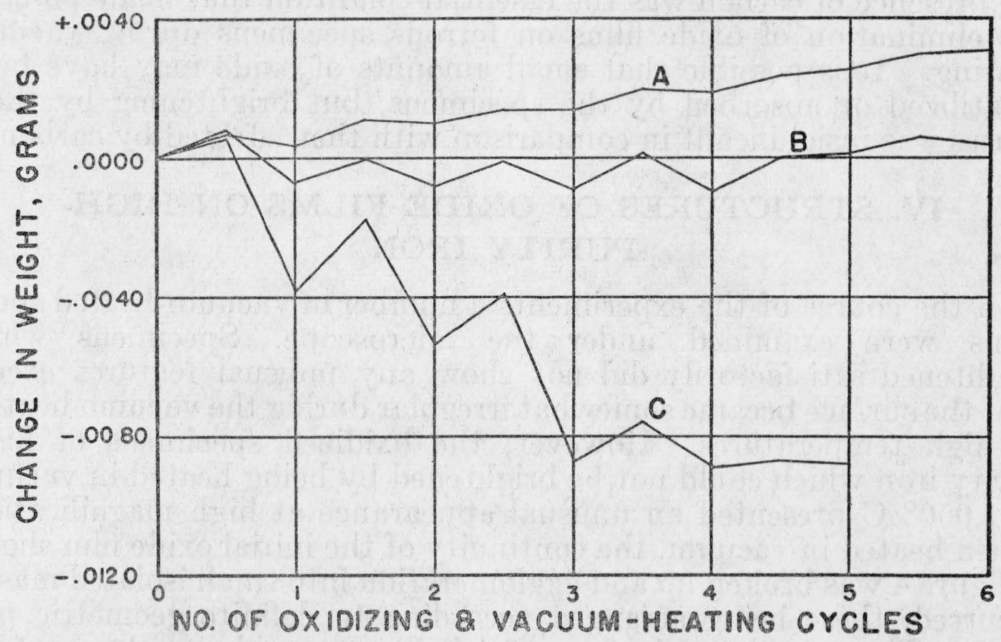

FIGURE 3.-Change in weight during repeated oxidation and vacuum-heating cycles for specimens of high-purity iron No. $2(A)$, electrolytic iron No. $4(B)$, and stainless steel No. $6(C)$.

Oxidation was at $400^{\circ} \mathrm{C}$ for the high-purity and electrolytic irons and at $800^{\circ} \mathrm{C}$ for the stainless steel. The electrolytic iron was vacuum heated at $800^{\circ} \mathrm{C}$, whereas temperatures of $1,050^{\circ} \mathrm{C}$ were used for the high. purity iron and the stainless steel.

Each curve is defined by two points for each cycle; the first point defines the change in weight during oxidation, the second, during vacuum heating.

The curve, $C$, for the stainless steel indicates distinctly greater changes in each cycle and a larger net loss in weight than that which occurred for electrolytic iron. This difference may be due partly to the fact that the stainless steel specimen underwent a greater change in carbon content, from 0.07 to 0.01 percent. It might be proposed that part of the loss was due to volatilization of oxide, but if this were true the specimen should have lost weight during the last cycle. However, the final vacuum heating did not cause any significant elimination of the oxide film. It is possible that some volatilization of metal may have occurred, although the experiments showed that the high-purity iron did not lose weight when vacuum-heated at the same temperature. Since complete clean-up occurred only in the first cycles, when the carbon content was sufficiently high, and because 
the specimen did not brighten or lose weight in the last cycle, when the carbon had been reduced to 0.01 percent, it appeared logical to assume that carbon was the essential agent in the brightening of the stainless steel just as in the case of electrolytic iron.

In all the experiments in this investigation, it appeared that the presence of carbon was necessary for the elimination of oxide films in vacuum heating. In all cases brightening could be associated with definite decreases in carbon content. Oxidized specimens of high-purity iron, which contained 0.001 percent or less of carbon, could not be brightened by heating in vacuum for the usual periods at temperatures up to $1,250^{\circ} \mathrm{C}$. The weight changes which were observed during oxidation and vacuum heating were generally of the correct magnitude to indicate that brightening occurred with the loss of oxygen as carbon monoxide. It is concluded, therefore, that the presence of carbon was the essential condition that made possible the elimination of oxide films on ferrous specimens during vacuum heating. It is possible that small amounts of oxide may have been volatilized or absorbed by the specimens, but brightening by these causes was insignificant in comparison with that effected by carbon..

\section{STRUCTURES OF OXIDE FILMS ON HIGH- PURITY IRON}

In the course of the experiments a number of vacuum-heated specimens were examined under the microscope. Specimens which brightened satisfactorily did not show any unusual features except that the surface became somewhat irregular during the vacuum heating at high temperatures. However, the oxidized specimens of highpurity iron which could not be brightened by being heated in vacuum at $1,050^{\circ} \mathrm{C}$ presented an unusual appearance at high magnification. When heated in vacuum, the continuity of the initial oxide film shown in figure 4 was broken up and agglomeration into small isolated masses occurred, these being arranged according to definite geometric patterns. The area shown in figure $5(A)$ illustrates the tendency of the agglomerated film to form square figures, as most of the lines intersect at right angles. In figure $5(B)$, the lines intersect at approximately 60-degree angles, with the result that the figures are triangular. Since the type and orientation of these patterns vary from grain to grain, it appears probable that they are related to the orientation in the underlying metal. Figure $5(C)$ shows an area at the junction of several grains. The tendency of some grains to oxidize to a greater degree than others, as indicated by the ratio of light to dark areas, is evident, and the orientation and nature of the pattern formed by the agglomerated oxide are different for different grains. The light areas between the globules indicate the background of bright metal. This bright metal would be capable of reoxidation, and in the oxidizing experiments this fact was verified. A blue color was developed during oxidation after each vacuum heating.

Figure $5(D)$ shows the appearance of one of the vacuum-heated specimens of high-purity iron that was polished on a cross section to show the thickness of the oxide globules.

When specimens of high-purity iron similar to those shown in figure 5 were heated to $1,250^{\circ} \mathrm{C}$ in vacuo, the oxide globules gathered into still larger masses, and the distinctness of the initial geometric patterns was lost. Some of the globules were located in the grain boundaries, 


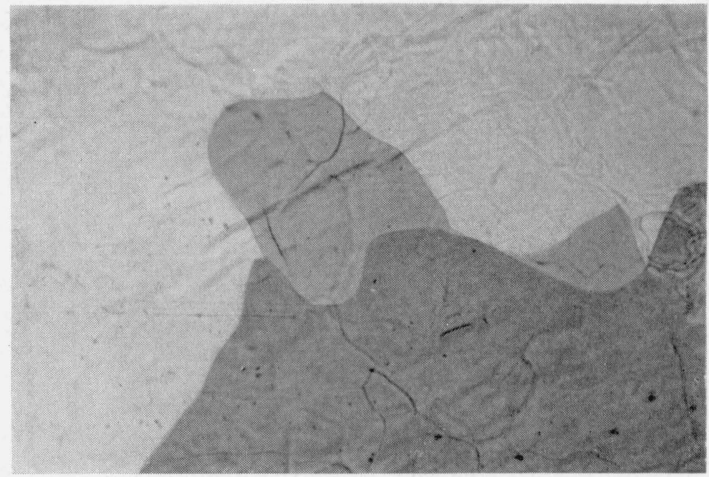

Figure 4.-Oxidized surface of high-purity iron; $\times 500$.

Oxidation at $400^{\circ} \mathrm{C}$ occurred in varying degree for different grains, as indicated by differences in interference colors. The light-gray areas in the micrograph represent a straw color in the specimen, whereas the darkest areas are dark brown. The blue areas, which photographed to give the intermediate-gray tone, represent the highest degree of oxidation. 

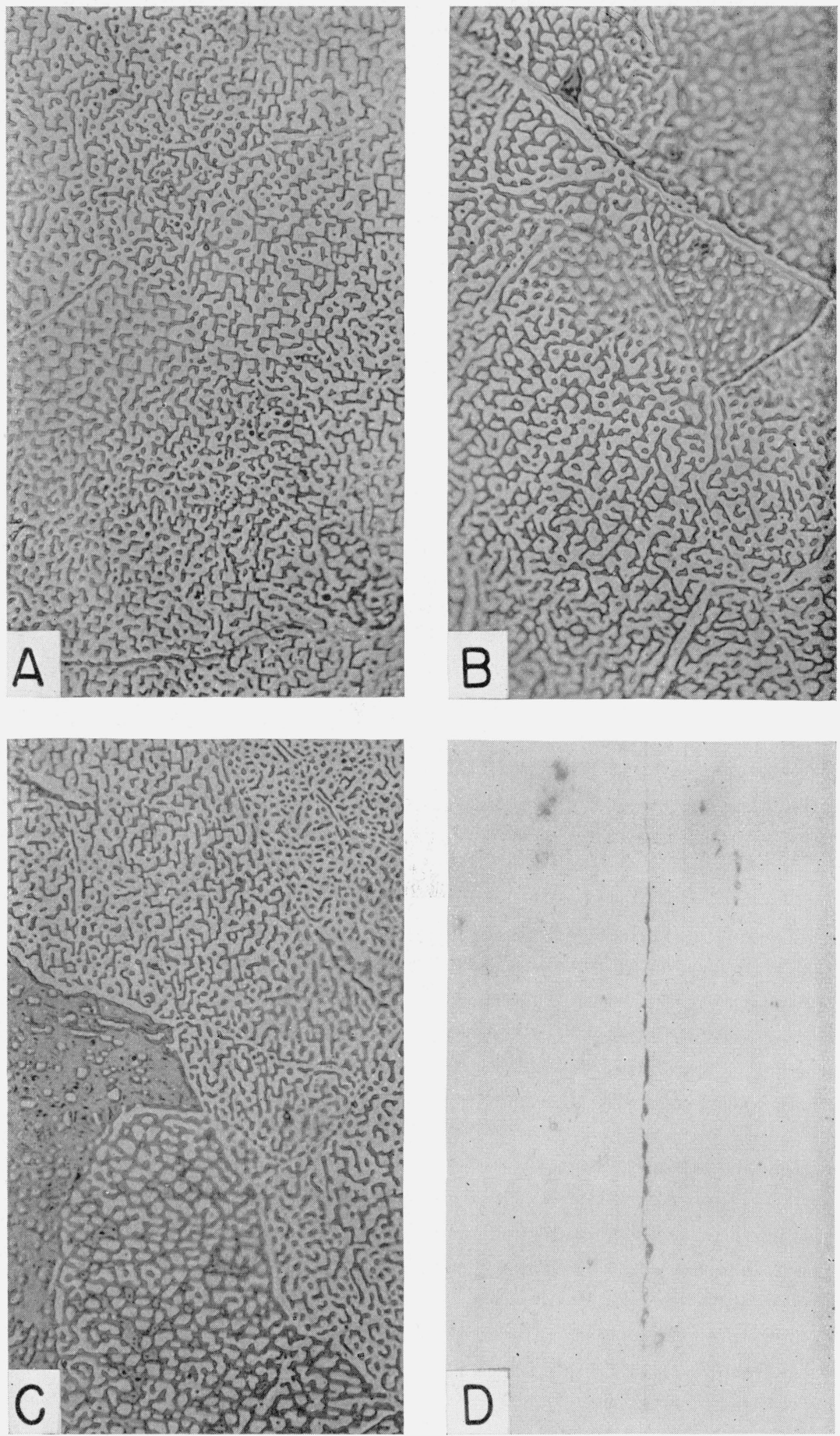

Figure 5.-Oxidized specimens of high-purity iron, vacuum-heated at $1,050^{\circ} \mathrm{C}$. $A, B$, and $C$ illustrate the surface appearance of specimens after vacuum heating. Note the geometric patterns outlined by the globules. $\times 500$.

$D$ is a micrograph of the polished cross section of the surface of one of the above specimens, showing the thickness of the oxide globules. The surface was protected by a layer of electrodeposited copper during polishing. $\times 1000$ 

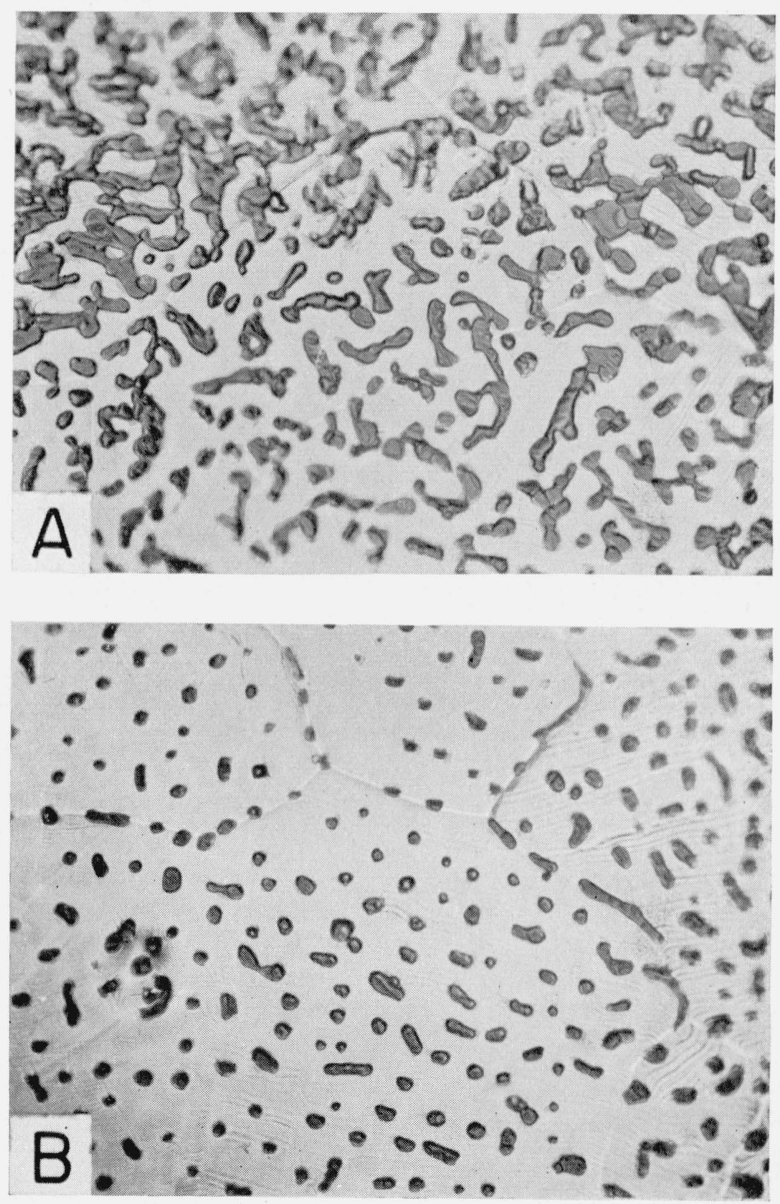

FIGURE 6.-Oxidized specimens of high-purity iron, vacuum heated at $1,250^{\circ}$ C.; $\times 500$.

$A$, coarse, globular structures formed at the higher temperature.
$B$, globules partly covered by condensed iron from the heating thimble. Note the globules in the grain boundaries. 
whereas others lay directly across the boundaries, extending from one grain to another. The appearance of two different areas of a specimen is shown in figure 6. During the heating at $1,250^{\circ} \mathrm{C}$, some iron vaporized from the heating thimble used as the container, and was condensed on the specimen. This was indicated by the partial brightening of the oxidized specimens through the deposition of a film of iron and by weight changes. The smaller number of globules in the area shown in figure $6(B)$ than in figure $6(A)$ perhaps can be attributed to the presence in this region of a thicker film of condensed iron in which many of the globules are embedded and hidden.

\section{SUMMARY}

Oxide films on ferrous materials - such as carbon steel, stainless steel, open-hearth iron, or electrolytic iron- that contain carbon may be removed by heating to suitable temperatures in a high vacuum. When oxide films are removed from such materials, there is an accompanying decrease in carbon content.

The clean-up of oxide films by vacuum heating can occur only if the carbon content is above a certain minimum value. For the conditions of heating that were used, this minimum was about 0.005 percent for iron and approximately 0.01 percent for stainless steel.

Oxide films on ferrous materials low in carbon, like high-purity iron, could not be removed by heating in vacuum for the period of time used for the carbon-bearing materials at temperatures up to $1,250^{\circ} \mathrm{C}$. This has been interpreted as showing that no significant brightening occurs either by thermal dissociation of oxides, volatilization of oxides, or by absorption of oxide films in the underlying metal.

When lightly oxidized specimens of high-purity iron were heated at about $1,050^{\circ} \mathrm{C}$ in vacuum, agglomeration of the initially continuous oxide film occurred, the small isolated masses being distributed on a background of bright metal. Sometimes the agglomerated oxide masses were arranged according to a geometric pattern which varied from one grain to another.

\section{REFERENCES}

[1] H. W. Gillett and B. W. Gonser, Fundamental Features of Controlled Atmospheres, Particularly for the Heat Treatment of Steel, Am. Soc. Metals Preprint (October 1941).

[2] C. A. Zapffe and C. E. Sims, Hydrogen, flakes and shatter cracks, a correlated abstract, Part II, Metals \& Alloys 12, 44 (1940).

[3] V. C. F. Holm, Observations on the tarnishing of stainless steels on heating in vacuo, Surface Treatment of Metals, p. 379 (American Society for Metals, 7301 Euclid Avenue, Cleveland, Ohio, 1941).

[4] J. G. Thompson and H. E. Cleaves, Preparation of high-purity iron, J. Research NBS 23, 163 (1939) RP1226.

[5] J. W. Mellor, A Comprehensive Treatise on Inorganic and Theoretical Chemistry, 13, 713 (Longmans, Green and Co., New York and London, 1934).

[6] B. W. Gonser, Discussion of paper by V. C. F. Holm (see reference 3), Surface Treatment of Metals, p. 389 (American Society for Metals, 7301 Euclid Avenue, Cleveland, Ohio, 1941).

[7] F. N. Rhines, A metallographic study of internal oxidation in the alpha solid solutions of copper, Trans. Am. Inst. Mining Met. Engrs., Institute of Metals Division, 13\%, 246 (1940).

[8] B. A. Rogers and K. O. Stamm, A magnetic determination of the $A_{3}$ transformation point in iron, Metals Tech. 8, TP1388 (1941).

WASHINGTON, January 30, 1942. 